\title{
DECRETOS, EMENDAS, E O FALAR BEM SOBRE AS IDEIAS - SOBRE NOTAS DE ARISTÓTELES A PLATÃO
} (Tóp. 137b) -

André Luiz Braga da Silva Doutorando em filosofia (USP)

Pois veja bem, ó nobre Críton: o falar incorretamente não é apenas incorrer em erro, mas fazer mal às almas.

Personagem Sócrates platônico

(poucos minutos antes da cicuta $)^{1}$

Palavras-chave: Aristóteles, Platão, Tópicos.

\section{Qua Aristóteles}

O texto dos Tópicos é famoso, entre outros motivos, por conter aquilo que se entende ser comentários do fundador do Liceu sobre a ontologia das Ideias que Platão apresentou em seus diálogos. A certa altura desse texto, é possível ler:

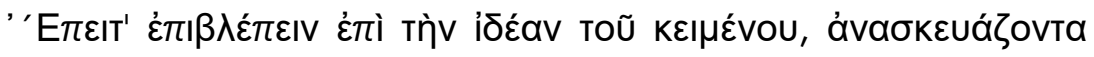

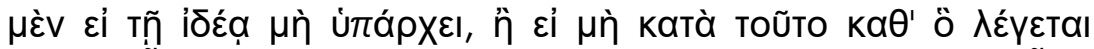

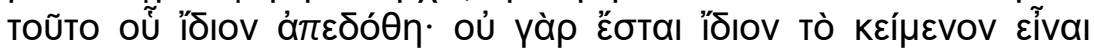

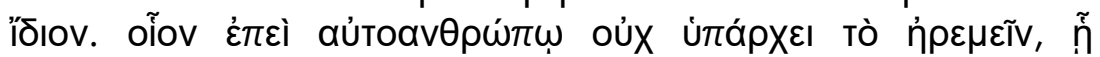

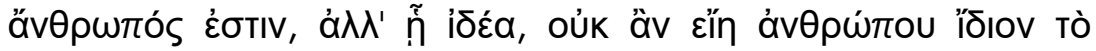

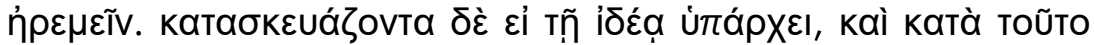

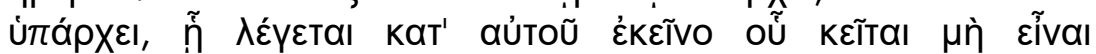

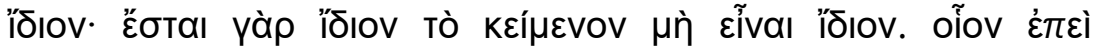

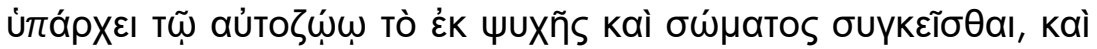

PLATÃO. Fédon 115e4-6. 
Decretos, emendas, e o falar bem sobre as Ideias

- sobre notas de Aristóteles a Platão (Tóp. 137b) - André Luiz Braga da Silva

AnaLógos, Rio de Janeiro, v. 1, 2016, p. 116-128

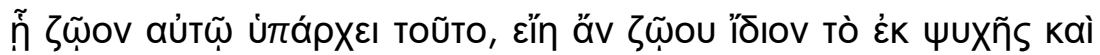

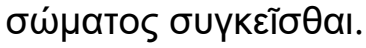

Considere-se [...] a ideia do sujeito proposto e veja-se, para fins de refutação, se a propriedade sugerida não pertence à ideia em questão, ou se deixa de pertencer-lhe devido àquela característica que the vale a descrição de que se enunciou a propriedade: pois, nesse caso, o que se afirmou ser uma propriedade não será tal. Assim, por exemplo, como o "estar em repouso" não pertence a Homem em Si com relação ao fato de ser homem, mas com relação ao fato de [ser] ideia, não seria propriedade de homem o "estar em repouso". Para fins construtivos, por outro lado, veja-se se a propriedade em questão pertence à ideia, e se the pertence sobre aquele aspecto devido ao qual se predica dele aquela característica de que se afirmou que o predicado em questão não era uma propriedade: pois, nesse caso, o que se negou que fosse uma propriedade será uma propriedade. Assim, por exemplo, como pertence a Animal em Si o "ser composto de alma e corpo", e isto pertence a ele com relação ao fato de [ser] animal, o "ser composto de alma e corpo" seria propriedade de animal.

(ARISTÓTELES. Tópicos 137b3-13² - grifos nossos)

Podemos citar a explicação de $\mathrm{H}$. Cherniss da passagem, a qual se harmoniza com o sentido que outros estudiosos nela viram (G. E. L. Owen, 1968; D. Keyt, 1969 e 1971; G. Vlastos, 1973b):

Pode-se refutar a atribuição de uma propriedade a um dado sujeito sob o fundamento de que ela não é uma propriedade da ideia correspondente no sentido no qual o sujeito ao qual a propriedade foi atribuída é referido, ou se pode demonstrar que um dado sujeito possui a propriedade a qual foi negada a ele em mostrando que a ideia correspondente possui essa propriedade e possui essa propriedade não enquanto ideia mas enquanto ideia do sujeito dado. Por exemplo, a imobilidade não pode ser predicada de homem como um proprium porque, enquanto ela é uma característica da ideia de homem

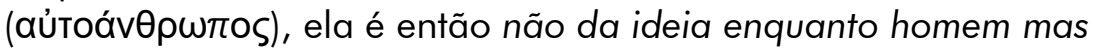
enquanto ideia; por outro lado, "complexo de corpo e alma", sendo uma característica da ideia de animal enquanto animal e não enquanto ideia, deve ser um proprium de animal. Em outras 1973 (Coleção Os Pensadores) - com modificações. 
- sobre notas de Aristóteles a Platão (Tóp. 137b) - André Luiz Braga da Silva

AnaLógos, Rio de Janeiro, v. 1, 2016, p. 116-128

palavras, a relação entre ideia e propriedade, de um lado, e entre sujeito e propriedade, do outro, é assumida ser idêntica, e a assunção requer a "análise" da ideia" [...].

(CHERNISS, 1946, p. 1-2 - grifos nossos)

Para pensar a ontologia das Ideias espalhada pelo corpus platonicum, a passagem aristotélica traz tanto interessantes bases de investigação quanto graves problemas de análise. $O$ ponto mais interessante parece ser a "relativização" da posse de certa qualidade por parte de um sujeito a determinados aspectos dele. Tal relativização é obtida na passagem através do dativo hêi , frequentemente traduzida pelo latino qua: Ideia de $X$ possui a qualidade $A$ enquanto (qua) $X$ (isto é, com relação ao fato de ser $X$, com relação à sua natureza própria de $X$ ), e possui a qualidade $B$ enquanto (qua) ideia (isto é, com relação ao fato de ser ideia, com relação à sua natureza própria de ideia). $\mathrm{Na}$ linguagem de Cherniss, a Ideia de X sofre assim uma "análise" em dois diferentes aspectos ou "momentos": características enquanto $X$, que podemos chamar de "Propriedades Próprias", e características enquanto ideia, que podemos chamar de "Propriedades Ideais".

\section{Qua Platão}

O primeiro ponto a ser tratado por mim é a compatibilidade ou não dessa relativização com aquilo que emana dos próprios diálogos platônicos. Vejamos então rapidamente três passagens dos mesmos. Em República V 454al-d3 há algumas afirmações sobre duas atividades ou 'técnicas' de argumentação diferentes, a "antilógica" e a "dialética". Sobre a primeira, é dito que seus adeptos, ao comparar duas coisas (" $X$ " e " $Y$ "), facilmente identificáveis como diferentes, afirmam simplesmente " $X \neq Y$ ", sem atentar para mais nada nisso. Assim, em seus jogos de contradições verbais, eles se divertem ao retirar da afirmativa conclusões absurdas, tais como: dado que concordamos que na cidade as pessoas diferentes não podem exercer a mesma atividade, e que "cabeludos" e "carecas" são diferentes, então concluise que, se os membros de um desses grupos poderem ser sapateiros, os membros do outro grupo não o poderão. Essas conclusões a que os adeptos dessa 'técnica' chegam são expressamente ditas serem "ridículas" (cf. geloîon, 454c6-6). Já da "dialética", é dito que seus adeptos, diante da mesma situação, procurariam estar atentos para "de que modo" (hopêi) e "com relação ao quê" (pròs ti) $X$ difere de $Y$, circunscrevendo suas conclusões à atenção a estas relações (454b6-9). Nesse sentido, a diferença entre os cabeludos e os carecas não diz respeito às naturezas de ambos que estão relacionadas às atividades que desempenham na cidade, mas apenas às suas condições 'capilares', podendo então os membros de ambos os grupos serem, sem problemas, sapateiros. $E$, mutatis mutantis, mulher e homem são diferentes, mas eles não 
diferem quanto às atividades 'desempenháveis' por cada um: "não há na cidade nenhuma atividade própria à mulher "devido ao fato de (dioti) [ser] mulher e [nem própria] ao homem devido ao fato de (dioti) [ser] homem, então ambos podem ter a mesma ocupação na cidade" (455d7-9).

Em Fédon 102b8-d3, o personagem Sócrates diz o seguinte: quando falamos simplesmente "Símias é maior que Sócrates", as palavras dispostas simplesmente desse jeito não dizem a "verdade" dos fatos. Porque, ele explica, Símias não é maior que Sócrates "por sua natureza" [de Símias] (pou pephykénai), i.e, "com relação ao fato de ser Símias" (tôi Simmían eînai, 102cl 2); o que ocorre de fato é que a grandeza do primeiro ultrapassa a pequenez do segundo. Em seguida, ele diz que Símias ultrapassa [em altura] Sócrates não "porque Sócrates é Sócrates" (hóti Sokkrátẹs ho Sokkrátês estín), mas porque Sócrates possui pequenez em relação à (pròs) grandeza daquele (102c2-4). Mais à frente, reparando no próprio modo em que colocou estas coisas, Sócrates sorri, dizendo: "Parece que estou a falar syngraphikôs" (102d1-2). O advérbio grego, cuja presente ocorrência é a única no corpus, significa "com muita precisão", mas não apenas isto: o substantivo syngraphé pode ser traduzido como "contrato", "tratado", "decreto"; e o verbo syngrápho significa "fazer um contrato escrito", "obrigar-se por escrito", "escrever emenda(s) a um decreto" (cf. Górgias 451 b7-cl). Ao, portanto, "melhorar" o modo como atribuir uma propriedade a um sujeito, Sócrates parece não estar apenas aumentando a "precisão" de sua fala, mas mesmo estar "corrigindo-se" (cf. a noção de "emenda legislativa") e "obrigando-se a aderir" a esta "correção" (cf. a noção de "contrato", "decreto"; e, ainda, BURGER, 1947)". Se, na cena da República, a ausência de relativização da posse de uma propriedade poderia levar a resultados pueris e ridículos, aqui, no Fédon, o aparecimento dessa relativização parece notável e surpreendentemente positivo: Sócrates pensa no que realizara, e sorri, dizendo que, ainda que estranhas, as coisas são do jeito que ele diz (cf. pou hôs légo, Fédon 102d3); logo, devem ser assumidas nesses termos, pois o falar de maneira incorreta é não apenas "errar" e "soar fora do tom" (cf. plêmmelés), mas, também, sobretudo: fazer mal às almas (Fédon 115e4-6).

E, em uníssono ao Fédon, no passo $71 d 4-72 d 3$ do Mênon - a famosa cena sobre definição de "virtude" - Sócrates e seu interlocutor chegam à conclusão de que todas as abelhas existentes não diferem nada em relação às características que as fazem abelhas, i.e, as características que elas possuem com relação ao fato de serem abelhas (tôi melíttas eînai, 72b4-5; hêi méllitai eisín, b8-9); dizer estas características é exibir a essência (ousía) de abelha $(72 b 1)$.

Que portanto extrair desses três trechos? Friso que este meu curto texto não é ocasião para entrar no mérito da gigante questão se Platão já antecipava ou não a diferenciação aristotélica entre atributos acidentais e essenciais. Todavia, a partir dessas passagens, no mínimo podemos ter certeza de que a 'relativização' da posse de determinada qualidade a algum aspecto de um sujeito não só não era estranha a Platão, como poder-lhe-ia ser significativa 
e reveladora desse sujeito. Isto no seguinte sentido: dizer as características de um animal com relação ao fato de ele ser animal é dar uma "definição" de animal", é delimitar a "essência" de "animal". Isto é, é dizer o que atravessa e é comum a todos os casos de animal, e cuja pertença é necessária para algo ser "animal". Do mesmo modo, podemos concluir que dizer as características de uma ideia com relação ao fato de ela ser ideia é dar uma "definição" de "ideia", é delimitar a "essência" de ideia. Isto é, é dizer o que atravessa e é comum a todos os casos de ideia, e cuja pertença é necessária para algo ser "ideia".

\section{Aristóteles dialogando com Platão}

Voltando a Aristóteles, munidos agora desses antecedentes platônicos, vimos que o estagirita traça uma distinção entre dois tipos de qualidades de uma Ideia: as qualidades da Ideias de $X$ com relação ao fato de ela ser X (as Propriedades Próprias), e as qualidades da Ideias de X com relação ao fato de ela ser ideia (as Propriedades Ideais). Vale dizer, esta distinção entre esses dois tipos de qualidades também ficou conhecida entre os comentadores como "Distinção-P" (VLASTOS, 1973b). No exemplo dado pelo fundador do Liceu (Tópicos 137b3-13, citado acima), uma das características cuja pertença é necessária para algo ser um "animal" é "possuir alma e corpo"; e uma das características necessárias para algo ser uma ideia platônica é a "estabilidade" ou "não sujeição à mudança" (isto é, "estar em repouso"). Portanto, segundo Aristóteles, a Ideia de Animal, enquanto animal, possui alma e corpo, e, enquanto ideia, é estável. Mas há algo de muito problemático na Distinção-P traçada nesses termos. Dentro dessa lógica aristotélica, esta distinção parte do pressuposto daquilo que ficou conhecido na literatura secundária como "Autopredicação": a Ideia correspondente inteligível da qualidade X seria, ela mesma, uma coisa " $X$ ", i.e, ela também possuiria a qualidade X. Por exemplo, a Forma de Justiça seria ela mesma uma coisa justa, e a Forma de Mesa seria ela mesma uma mesa. Exemplos desse entendimento aristotélico não faltam (Tópicos 154a16-20; Ética a Nicômaco I 6 1096a34-b5; etc); contudo, se correto, ele geraria uma série de impossibilidades no pensamento platônico. Olhando para a Propriedade Própria e a Propriedade Ideal que Aristóteles apresentou nos Tópicos da Ideia de Animal, não é difícil ver que, pelo exposto nos diálogos, essas duas propriedades são incompatíveis entre si. Do ponto de vista do corpus platonicum, "alma" é princípio de movimento e mudança; e "corpo" é algo sujeito à mudança. Uma Ideia é algo por definição não sujeito à mudança, algo estável, e sempre incorpóreo. Então, conforme muito bem mostrado por Cherniss (1946) e Vlastos (1973b), a Distinção-P em termos aristotélicos seria inaceitável para Platão, pois ela está fundamentada na Autopredicação (cf. também OWEN, 1968; KEYT; 1969 e 1971; SANTAS, 1980); e a Autopredicação, se fosse aceita como regra geral para todas as Ideias, destruiria parte fundamental daquilo que é chamado em alguns estudos de 
"Hipótese das Formas" ou "Teoria das Ideias" platônica (VLASTOS, 1972). Expliquemos melhor como se daria essa destruição com alguns exemplos: se a Ideia é por definição incorpórea, eterna, intangível, imortal - logo, uma entidade incapaz de qualquer forma de vida ou de tomar qualquer decisão e realizar escolhas -, que sentido poderia haver então em dizer que uma Ideia é ela mesma "corajosa" (para a Ideia de Coragem)? Ou dizer que uma Ideia é ela mesma um "artefato" (para a Ideia de Escudo)? Ou que alguma Ideia possui alma e corpo (para a Ideia de Animal)? Ou que um ente inteligível, sem corpo (intangível) e sem formato (cf. anaphès; aschenátistos: Fedro 247c6-7), é ele mesmo "retangular" (no caso da Ideia de Retângulo)? Segundo Vlastos (1973b), no que concordaria Cherniss (1946), o problema da concepção aristotélica da Ideia como autopredicativa é que esta concepção está carregada demais, carregada com a ontologia que não é de Platão, mas do próprio Aristóteles. Segundo tais autores, o estagirita foi quem entendeu seus "universais" como imanentes e sendo "apenas os atributos comuns das classes dos particulares" (p. ex., Metafísica 1040b32-34; 105913-14; 1086b10-11); seu antigo mestre, não (VLASTOS, 1973b; CHERNISS, 1946).

\section{Um ponto positivo}

Entretanto, como vimos, a relativização, que Aristóteles apresenta nos Tópicos, da posse de uma qualidade por um sujeito, foi não só utilizada por Platão em outros contextos, como parecia ter, nestes momentos, mesmo uma marcada importância: o personagem Sócrates platônico diz que falar sem tomar esse cuidado é não falar a verdade (Fédon 102b7-1), é não ser digno de ser considerado dialético, mas estar sujeito a conclusões pueris e ridículas (República V 454a 1-d3). Então, esse tipo de "cuidado", que assemelha o filósofo a um legislador que com grande precisão elabora emendas a decretos (Fédon 102d2-3), pode ser especialmente importante na ontologia platônica, porque contribui para melhor iluminação das essências (ousíai) de que ela trata... Ora, diante dessa aparente importância e utilidade da tal "análise da ideia" (CHERNISS, 1946) que a Distinção-P representa, poderíamos nos perguntar: é possível traçar uma nova Distinção-P (isto é, uma distinção por relativização dos atributos da ideias platônicas) que, diferentemente daquela traçada por Aristóteles (Tópicos 137b3-13), seja compatível com a ontologia apresentada nos diálogos?

\section{Resumo e mais dois conceitos}

Antes de sugerir essa nova possibilidade, penso ser útil repassar os pontos vistos até aqui, além de explicar mais dois conceitos que serão úteis a esta sugestão: 
a) o básico da ontologia platônica é que existem dois modos de ser diferentes na realidade: o modo de ser das "Formas" ou "Ideias", e o das "instâncias sensíveis"; são propriedades das Ideias mas não das instâncias sensíveis: serem eternas, únicas, imutáveis, essências (ousíai), com realidade em si e por si, e passíveis de intelecção mas não de sensação; são propriedades das instâncias sensíveis mas não das Ideias: serem 'perecíveis', múltiplas, mutáveis, da ordem da génesis, com realidade dependente em relação às Formas (ao modo da "semelhança" e "participação"), e passíveis de sensação mas não de intelecção (cf., p. ex., República V, 476a4-d4; 478c7-480a13; VI, 484b3-4; 485b1-3; 486d9-10; 490b2-4; 493e2-494a5; 500b8-c5, 507b2-c2).

b) "participação": a princípio, é a relação entre instância sensível e Ideia, sendo uma relação causal através da qual a instância possui a qualidade da qual a Ideia que é o correspondente inteligível dessa qualidade (Fédon 100b5-c8 e alhures);

c) "Autopredicação": Dizer que ocorre a uma Forma ou Ideia o fenômeno da "Autopredicação" (ou "Autoexemplificação", "Autocaracterização") significa dizer a Forma não é apenas o correspondente inteligível de determinada qualidade, mas que efetiva e literalmente a própria Forma é uma "instância" da qualidade a que ela corresponde, isto é, que ela "exemplifica" ou "possui" a qualidade da qual ela é o correspondente (ALLEN, 1960; VLASTOS, 1965, 1965/1966, 1969, 1972, 1973a e 1973b; NEHAMAS, 1972; etc);

d) antiga Distinção-P: distinção estabelecida no texto aristotélico dos Tópicos entre dois tipos de atributos identificáveis numa Ideia platônica atributos posteriormente batizados, entre outras alcunhas, de Propriedades Próprias e Propriedades Ideais;

e) "Propriedades Próprias": propriedades da Ideia de $\mathrm{X}$ que ela possui enquanto $\mathrm{X}$, por ser $\mathrm{X}$;

f) "Propriedades Ideais": propriedades da Ideia de X que ela possui enquanto Ideia, por ser Ideia;

g) Conclusão Parcial: a assunção pura e simples da Autopredicação como regra geral implicaria as Ideias possuírem simultaneamente Propriedades Ideais e propriedades exclusivas das instâncias sensíveis, o que é incompatível com a ontologia platônica. Logo, a Autopredicação como regra geral não se coaduna com algumas das afirmativas mais fundamentais nos diálogos sobre as 
ideias; e, por conseguinte, tampouco se coadunaria com os diálogos a Distinção-P aristotélica, que é baseada na lógica autopredicativa (VLASTOS, $1965 ; 1965 / 1966 ; 1972 ; 1973 b)$.

h) apresentação de dois novos conceitos: "Predicação Ordinária" e "Predicação Paulina":

No tratamento de nossa matéria, Vlastos identifica dois tipos de maneiras de um enunciado atribuir uma propriedade a (ou "predicar um atributo de") algo; e ele chamou essas duas maneiras de "Predicação Paulina" e "Predicação Ordinária" (esta última também chamada por alguns de "nãoPaulina"). A novidade, conforme veremos, é a primeira, a "paulina", haja vista ela fazer apelo a uma demora maior, por parte do intérprete do enunciado, sobre o real sentido da assertiva que a contém. De início, Vlastos procurará mostrar justamente que, ainda que seu esmiuçamento nos cause espécie, esse tipo de predicação é recorrente e perfeitamente normal na linguagem a que estamos todos habituados a empregar. Para evidenciar isso, o estudioso dará dois exemplos aceitáveis de ocorrência perfeitamente detectável de Predicação Paulina (VLASTOS, 1972): um em grego antigo (em koiné), outro em inglês ambas as passagens citadas já traduzidas:

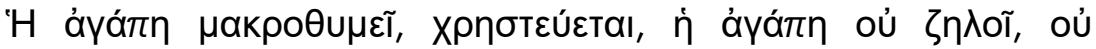

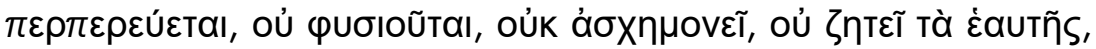

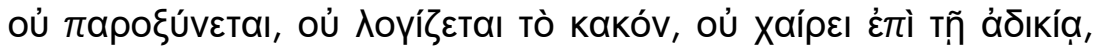

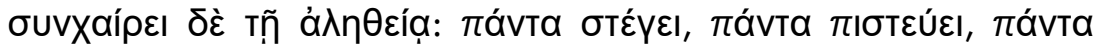

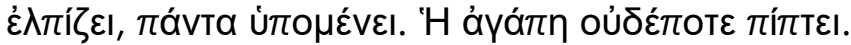

A caridade é paciente, é benigna. A caridade não arde em ciúmes, não se ufana, não se ensoberbece, não se conduz inconvenientemente, não procura os seus interesses, não se exaspera, não se ressente do mal; não se alegra com a injustiça, mas regozija-se com a verdade; tudo sofre, tudo crê, tudo espera, tudo suporta. A caridade jamais acaba.

(1 Corínthios 13, 4-8 - trad. de J. F. Almeida, como modificações)

O melhor tipo de coragem (aquela a qual faria um homem agir sem egoísmo num campo de concentração) é inabalável, calmo, temperante, inteligente, amável [...].

(MURDOCH, 1970, p. 57, apud VLASTOS, 1972, p. 253)

Em relação ao primeiro exemplo, o comentador turco afirma que, seja os próprios destinatários (os coríntios), seja nós mesmos hoje em dia, qualquer um que lesse a epístola do apóstolo Paulo entenderia que ele estava 
"obviamente predicando "paciência" e "bondade" daqueles que têm a virtude da caridade", e nada de diferente disso (VLASTOS, 1972, p. 253). Isto é, seria absurdo arguir que algum homem são entenderia que, na sentença bíblica acima, uma qualidade moral como paciência estivesse literalmente sendo atribuída a uma outra qualidade moral, a caridade, que como tal é uma entidade igualmente abstrata e sem possibilidade de ser ela mesma "paciente" ou "impaciente". E o mesmo vale para a sentença de Murdoch, citada na sequência: o único sentido razoável que existe na mesma é: quem quer que tenha coragem (isto é, que seja "corajoso"), será também "inabalável", "calmo", "temperante", "inteligente" e "amável". Senão, que sentido poderia haver em dizer que a coragem ela mesma, enquanto qualidade moral, é... "inteligente"? Poderia uma qualidade abstrata ser... "amável" ou "intratável" com alguém?

A partir dessas explicações, podemos agora definir os dois tipos de predicação identificados por Vlastos em sentenças envolvendo qualidades (1972, p. 235-239; 253-254; 1973, p. 272-274):

"Predicação Ordinária": é quando a propriedade atribuída na sentença à qualidade é para ser entendida como sendo literalmente atribuída à qualidade mesma, enquanto entidade abstrata. Assim como em "Abraão é pio" a piedade está sendo atribuída ao próprio Abraão, nas sentenças "Justiça é um universal", "Justiça é definível", "Justiça é uma propriedade moral", os predicados são para serem entendidos como sendo atribuídos literalmente à "Justiça", "entidade abstrata" (na linguagem vlastosiana), ou "Ideia inteligível" (na linguagem platônica) ${ }^{3}$.

"Predicação Paulina": é quando a propriedade atribuída na sentença à qualidade é para ser entendida como sendo literalmente atribuída não a ela mesma, entidade abstrata, mas sim a toda e qualquer instância que houver dessa qualidade, e isso de maneira necessária. Em linguagem platônica: tratase da atribuição literal da qualidade não à própria Ideia inteligível, mas sim às suas instâncias, de maneira obrigatória. Portanto, sentenças do tipo "paulino" (em vocabulário vlastosiano), como "Justiça é Imparcial" (ou "Justiça é cega") e "Coragem é sábia", se fossem traduzidas em predicação ordinária, ficariam assim:

O presente trabalho não é ocasião para entrar no mérito de se o tratamento como "qualidades abstratas" ou como "conceitos lógico-linguísticos” é ou não apropriado para as Ideias platônicas. Entretanto, sobre isso, eu gostaria de opinar apenas duas coisas: i) eu considero legitima a critica empreendida a este tratamento por autores como Dixsaut (2001); contudo ii) eu não considero que as questões (como a respeito de Autopredicação e Predicação Paulina) levantadas por Vlastos nos artigos mencionados neste meu texto deixem de existir mesmo se efetuarmos a "correção" (reclamada por Dixsaut) da visão 'lógica' para a 'ontológica'. Por exemplo, o fato de eu chamar as Ideias de "entidades inteligíveis reais" em vez de "entidades abstratas" ou "conceitos" não faz com que a Autocaracterização delas, como regra geral, deixe de conduzir a absurdos. 
"Justiça é imparcial" (Pred. Paul.) = "Se houver algum homem justo (i.e, uma instância de Justiça), ele necessariamente será também imparcial" (Pred. Ord.)

"Coragem é sábia" (Pred. Paul.) = "Se houver algum homem corajoso (i.e, uma instância de Coragem), ele necessariamente será também sábio" (Pred. Ord.)

E o mesmo vale para toda sentença interpretada como paulina: "Justiça é pia", "Coragem é inabalável", "Caridade é benigna", etc. Assim, em termos de ontologia platônica decodificada na linguagem de Vlastos: uma "Predicação Paulina" de uma Ideia inteligível representaria uma Predicação Ordinária necessária para todas as instâncias que porventura participem nessa Ideia. Exemplo: a sentença "Homem em Si (ou a Ideia de Homem) é mortal", lida como Predicação Paulina, poderia ser traduzida em Predicação Ordinária assim: "toda instância da Ideia Homem (todo "homem" particular) que houver será necessariamente mortal".

\section{Encaminhamentos Finais: uma nova Distinção-P}

Saliento que vou procurar, em minha proposta, dialogar com as definições de propriedades que os comentadores abordados, a partir de Aristóteles, utilizaram, seja incorporando-as, seja explicitando o motivo da rejeição, de acordo com a oportunidade. Considerando o que é afirmado sobre as entidades inteligíveis nos diálogos, aos meus olhos, então, é possível identificar três tipos de propriedades numa Ideia inteligível platônica:

"Propriedades Ideais": São as propriedades que são exclusivas das Ideias e que as diferenciam das instâncias sensíveis. Nesse sentido, é perfeitamente possível dizer que tais qualidades são as causas do que Franco Ferrari (2003) chamou de "separação ontológica". Chamo atenção que, com minha definição a seguir das "propriedades ideais", pretendo incorporar as definições de Owen (1968) e de Keyt (1969 e 1971), e até a concepção aristotélica: trata-se de propriedades que todas as Ideias têm, cuja ausência de algo implicaria que algo não fosse uma Ideia platônica (noção de "necessidade"); e são também propriedades da Ideia qua Ideia, i.e, com relação ao fato de ser Ideia.

"Propriedades Definidoras": São as propriedades que definem a Ideia específica que cada Ideia é. $E$, lembrando dos dois tipos de predicação que Vlastos demonstrou, tais propriedades são atribuídas às Ideias na modalidade de Predicação Paulina - o que significa que, se houver alguma instância dessas Ideias, tais propriedades lhe são necessariamente atribuídas, e atribuídas na modalidade de Predicação Ordinária. Ao dizer então "Homem é um animal bípede", não se está atribuindo literalmente (i.e: em Predicação Ordinária) à própria Ideia Homem a posse de alma e corpo, ou de dois pés; o que está 
sendo dito é que, se houver alguma instância desta Ideia (se existir algum "homem"), ele necessariamente deverá ter alma e corpo, bem como the ser natural andar sobre dois pés. Como não é difícil ver, a atribuição destas "propriedades definidoras" às instâncias por uma Ideia é a tradução, na linguagem da predicação (cunhada pelos comentadores analíticos), da relação causal entre Ideia e instância conhecida no corpus por "participação". Com esta minha definição, eu tento absorver o que de positivo havia nas definições de Keyt e Owen para os "atributos próprios" ("propriedades da Ideia de X qua Ideia de X"; "propriedades que definem a Forma específica que a Forma é"), não me vendo contudo obrigado a assumir a autopredicação que tais comentadores consideravam implicada em suas definições.

"Propriedades Existenciais": São comuns a Ideias e instâncias na modalidade de Predicação Ordinária para ambas. Exemplos de Propriedades Existenciais: existência, identidade e alteridade. Frise-se que as instâncias não recebem estas propriedades através da participação nas Ideias correspondentes inteligíveis destas instâncias, mas sim nas ldeias correspondentes inteligíveis destas próprias qualidades. De fato, possuímos obra platônica que deixa claro que tais propriedades são causadas pelos chamados "Gêneros Supremos" (mégista géne): Ideia de Ser, Ideia de Mesmo e Ideia de Outro (Sofista 250d259a). Nesse sentido, a instância sensível "este escudo de madeira" não é o mesmo que si mesmo por participação na Ideia de Escudo, mas sim por participação na Ideia de Mesmo.

Se pudermos aceitar essa nova versão da Distinção-P, então poderemos ver a sua utilidade para iluminar alguns aspectos da ontologia platônica, como, p.ex., a dinâmica da "participação" (cf. OWEN, 1968; KEYT, 1969 e 1971; VLASTOS, 1973b). Considerando a definição que forneci acima de "participação", a partir de Fédon 100b5-c8, é possível agora reescrevê-la usando a Distinção-P recém sugerida: quando uma instância participa numa Ideia, é a posse das Propriedades Definidoras da Ideia que a Ideia causa em sua instância. Isto é, a participação de uma instância em uma Ideia faz com que instância possua não as Propriedades Ideais da ldeia, mas sim a suas Propriedades Definidoras.

Ora, lembrando de uma passagem citada mais acima do Fédon, vimos o personagem Sócrates, visando "falar bem" e não "fazer mal às almas", aumentar a precisão no falar certas coisas (syngraphikôs ereîn, 102b8-d3); o advérbio grego, conforme comentamos, pode também significar "escrever emendas a um decreto", "escrever um contrato". Tendo em vista a demonstrada incompatibilidade da Distinção-P traçada no texto aristotélico (Tópicos 137b313), bem como a Nova Distinção-P sugerida por nós acima, poderíamos nos perguntar: se considerássemos a distinção realizada por Aristóteles um "decreto" deixado para a posteridade, poderíamos então considerar que estamos nós também a "falar bem", escrevendo como que uma "emenda", 
Decretos, emendas, e o falar bem sobre as Ideias - sobre notas de Aristóteles a Platão (Tóp. 137b) - André Luiz Braga da Silva AnaLógos, Rio de Janeiro, v. 1, 2016, p. 116-128

"emenda" a um tal "decreto" metafísico - escrito pelo estagirita a respeito do difícil, imbricado e milenar problema das Ideias inteligíveis platônicas -?

Pois veja bem, ó nobre
Críton: o falar
incorretamente não é
apenas incorrer em erro,
mas fazer mal às almas.
Personagem Sócrates
platônico
(poucos minutos antes da
cicuta) ${ }^{4}$

\section{Bibliografia}

ALLEN, R. E. Participation and Predication in Plato's Middle Dialogues. In Idem (ed.). Studies in Plato's Metaphysics. London: Routledge and Kegan Paul, 1967 (1960), p. 43-60.

ALLEN, R. E. Plato's Parmenides. London: Routledge \& Kegan Paul, 1997.

ARISTÓTELES. Tópicos. Tradução de L. Vallandro e G. Bornheim. São Paulo: Abril Cultural, 1973 (Coleção Os Pensadores).

ARISTOTLE. Posterior Analytics. Topica. Transl. by H. Tredennick and E. S. Forster. Cambridge: Harvard University Press, 1955.

BÍBLIA SAGRADA. Tradução J. F. de Almeida. São Paulo: Sociedade Bíblica do Brasil, 1993.

CHERNISS, H. Aristotle's criticism of Plato and the Academy. Baltimore: Johns Hopkins Press, 1946 (1944).

CHERNISS, H. F. "Parmenides and the Parmenides of Plato". The American Journal of Philology, vol. 53, no. 2 (1932), p. 122-138.

CORNFORD, F. M. Plato and Parmenides. Parmenides' way of truth and Plato's Parmênides. London: Routledge \& Kegan Paul, 1950.

DIXSAUT, M. Métamorphoses de la dialectique dans le dialogues de Platon. Paris: Vrin, 2001.

FERRARI, F. "L'idea del bene: collocazione ontologica e funzioni causale". In PLATONE. La Repubblica. Vol. V. Traduzione e commento a cura di Mario Vegetti. Napoli: Bibliopolis, 2003.

FINE, G. (ed.) Plato. 1, Metaphysics and Epistemology. Oxford: Oxford University Press, 1999. 
Decretos, emendas, e o falar bem sobre as Ideias - sobre notas de Aristóteles a Platão (Tóp. 137b) - André Luiz Braga da Silva AnaLógos, Rio de Janeiro, v. 1, 2016, p. 116-128

FRONTEROTTA, F. METHEXIS. La teoria platonica delle idee e la partecipazione delle cose empiriche. Pisa: Scuola Normale Superiore, 2001.

KEYT, D. "Plato's paradox that the Immutable is Unknowable". Philosophical Quartely 19 (1969), p. 1-14.

KEYT, D. "The mad craftsman of the Timaeus". Philosophical Review 80 (1971), p. 230-235.

KRAUT, R. (ed.) Plato's Republic: Critical Essays. New York: Rowman \& Littlefield, 1997.

MURDOCH, I. The sovereignty of Good. London: Routledge \& Kegan Paul, 1970.

NATORP, P. Plato's Theory of Ideas. Sankt Augustin: Academia Verlag, 2004 (1903).

NEHAMAS, A. "Participation and Predication in Plato's Middle Dialogues". The Review of Metaphysics (1972).

OWEN, G. E. L. Dialectic and Eristic in the treatment of Forms. In idem (ed.). Aristotle on Dialectic: the Topics. Proceedings of the Third Symposium Aristotelicum. Oxford: Clarendon Press, 1968, p. 103-125.

PLATONE. Parmenide. Introduzione, traduzione e note de Franco Ferrari. Milano: Biblioteca Universale Rizzoli, 2004.

ROSS, W. D. Plato's Theory of Ideas. Oxford: Clarendon Press, 1953 (1951).

RYLE, G. "Plato's Parmenides". Mind, vol. 48, no. 190 (1939).

SANTAS, G. "The Form of the Good in Plato's Republic". Philosophical Inquiry (1980). Reeditado em: ANTON, J. P.; PREUS, A. (ed.) Essays in Ancient Greek Philosophy vol. II. Albany: State University of New York Press, 1983; e em FINE, G. (ed.) Plato. 1, Metaphysics and Epistemology. Oxford: Oxford University Press, 1999.

SCOLNICOV, S. Plato's Parmenides. Berkeley: University of California Press, 2003.

SHIELDS, C. "Surpassing in Dignity and Power: The Metaphysics of Goodness in Plato's Republic". In ANAGNOSTOPOULOS, G. (ed.). Socratic, Platonic and Aristotelian Studies: Essays in Honor of Gerasimos Santas. London: Springer Science+Business Media, 2011.

SILVA, A. L. B. "Sobre um problema na interpretação de "eînai" e "ousía" no símile do Sol de Platão (República VI 509b)". Revista do Seminário dos Alunos do PPGLM-UFRJ, V. 5, n. 1 (2014) (disponível em https://seminarioppglm.wordpress.com/revista-do-seminario-dos-alunos-doppglm/ - página de internet, acesso em 23/12/2015, às 11:15).

SILVA, A. L. B. "Ideias de Bem e de Belo, os fótons da filosofia? - uma discussão com Gerasimos Santas arbitrada por G. Vlastos". Investigação Filosófica, Vol. 6 Edição especial do I Encontro Investigação Filosófica (2015), p. 62-79 (disponível em http://periodicoinvestigacaofilosofica.blogspot.com.br/ - página de internet, acesso em 18/12/2015, às 15:03).

VLASTOS, G. A metaphical paradox. In Idem. Platonic Studies. Princeton: PUP, 1973 (1965/1966), p. 5-19. 
Decretos, emendas, e o falar bem sobre as Ideias - sobre notas de Aristóteles a Platão (Tóp. 137b) - André Luiz Braga da Silva AnaLógos, Rio de Janeiro, v. 1, 2016, p. 116-128

VLASTOS, G. Degrees of reality. In Idem. Platonic Studies. Princeton: PUP, 1973 (1965).

VLASTOS, G. Reason and Causes in the Phaedo. In Idem. Platonic Studies. Princeton: PUP, 1973 (1969).

VLASTOS, G. The "Two-Level Paradoxes" in Aristotle. In Idem. Platonic Studies. Princeton: PUP, 1973.

VLASTOS, G. The Unity of Virtues in the Protagoras. In Idem. Platonic Studies. Princeton: PUP, 1973 (1972).

VLASTOS, G. An Ambiguity in the Sophist. In Idem. Platonic Studies. Princeton: PUP, 1973. 